\title{
IL-34 causes inflammation and beta cell apoptosis and dysfunction in gestational diabetes mellitus
}

\author{
Chenghao Piao ${ }^{1}$, Xiaojie Wang 2 , Shiqiao Peng ${ }^{3}$, Xinyu Guo ${ }^{4}$, Hui Zhao ${ }^{5}$, Li He ${ }^{6}$, Yan Zeng ${ }^{4}$, Fan Zhang ${ }^{3}$, Kewen Zhu ${ }^{2}$ \\ and Yiwei Wang ${ }^{2}$ \\ ${ }^{1}$ Department of Radiology, The Second Affiliated Hospital of Shenyang Medical College, Shenyang City, Liaoning Province, People's Republic of China \\ ${ }^{2}$ Department of Human Anatomy, Shenyang Medical College, Shenyang City, Liaoning Province, People's Republic of China \\ ${ }^{3}$ Department of Endocrinology and Metabolism, Institute of Endocrinology, Liaoning Provincial Key Laboratory of Endocrine Diseases, The First Affiliated \\ Hospital of China Medical University, Shenyang City, Liaoning Province, People's Republic of China \\ ${ }^{4}$ Department of Obstetrics, The Second Affiliated Hospital of Shenyang Medical College, Shenyang City, Liaoning Province, People's Republic of China \\ ${ }^{5}$ Department of Laboratory Medicine, The Second Affiliated Hospital of Shenyang Medical College, Shenyang City, Liaoning Province, \\ People's Republic of China \\ ${ }^{6}$ Department of Gastroenterology, The Second Affiliated Hospital of Shenyang Medical College, Shenyang City, Liaoning Province, \\ People's Republic of China
}

Correspondence should be addressed to Y Wang: wangyiwei_symc@163.com

\begin{abstract}
Objective: Gestational diabetes mellitus (GDM) is characterized by glucose intolerance during gestation. It is associated with a series of maternal and foetal complications. Interleukin (IL)-34 is a recently discovered pro-inflammatory cytokine that functions as a ligand for colony-stimulating factor-1 receptor (CSF-1R). The contribution of IL-34 in the development of multiple chronic inflammatory diseases and autoimmune diseases has been recently discovered. The aim of this study was to evaluate whether IL-34 participates in the pathogenesis of GDM.

Method: A total of 120 women were enrolled in this study, which included 60 GDM patients and age- and sex-matched healthy pregnant women. The expression of IL-34 in serum, cord blood and placental tissues was analysed by ELISA and Western blot assays. The association between IL-34 levels and clinical features was also studied. We additionally evaluated the effect of recombinant mouse IL-34 (rmIL-34) on apoptosis and pancreatic $\beta$ cell function.

Results: We found that IL-34 expression is highly increased in serum, cord blood and placental tissues in patients with GDM. In addition, there was a positive association between serum IL-34 and insulin resistance and glucose concentrations. Our data also revealed that IL-34 contributes to the apoptosis of pancreatic $\beta$ cells in GDM caused by CSF-1R. Furthermore, functional studies found that IL-34 inhibited pancreatic $\beta$ cell function and cell viability, while CSF-1R inhibitor blocked this effect.

Conclusion: IL-34 plays a crucial role in the development of GDM by targeting CSF-1R, insulin production and $\beta$ cell function.
\end{abstract}

\author{
Key Words \\ - gestational diabetes \\ mellitus \\ - IL-34 \\ - CSF-1R \\ - apoptosis \\ - pancreatic $\beta$ cell
}

https://ec.bioscientifica.com

https://doi.org/10.1530/EC-19-0436 (c) 2019 The authors Published by Bioscientifica Ltd

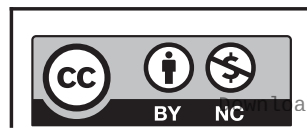

This work is licensed under a Creative Commons Attribution-NonCommercial 4.0 International License. ded from Bioscientifica.com at 04/26/2023 10:40:13AM
Endocrine Connections (2019) 8, 1503-1512 


\section{Introduction}

Insulin sensitivity during pregnancy is reduced with the advancement of gestation. Thus, the demand for insulin is elevated to maintain the common blood sugar (1). Gestational diabetes mellitus (GDM) is characterized by glucose intolerance of diverse severity with onset or first validation during pregnancy (2). It is one of the most common gestational complications and affects approximately $25 \%$ of all pregnant women. GDM is of high risk for mothers and new-borns and results in an elevated rate of foetal mortality (3). Moreover, patients with GDM are prone to developing type 2 diabetes and obesity in later life (4).

Insulin sensitivity is reduced by approximately $60 \%$ during gestation to provide sufficient blood sugar to the foetus for development (5). The need for maternal insulin is an elevated result of gestational insulin resistance, which is impacted by attenuated food intake and placental hormone production. Consequently, the sizes of pancreatic $\beta$ cells are enhanced to compensate for the elevated maternal glucose levels (6). The amount of $\beta$ cells is highly increased, and the insulin concentration of $\beta$ cells is lessened via the secretion of prolactin and placental growth factors (7). Therefore, the dysfunction of pancreatic $\beta$ cells is correlated with the pathogenesis of GDM. A significant association between GDM and inflammation has been reported (8). Highly secreted proinflammatory cytokines, such as IL- 6 , TNF- $\alpha$ and IL-1 $\beta$, contribute to the insulin signalling pathways, which lead to the deficiency of pancreatic cells (9). Interleukin (IL)-34 is a recently discovered pro-inflammatory cytokine that is composed of 242 amino acids (10). Moreover, IL-34 can bind with the extracellular domain of colony-stimulating factor 1 receptor (CSF-1R), resulting in phosphorylation of the intracellular tyrosine residues, which causes cell proliferation and differentiation (11). Recently, it has been reported that IL-34 also binds to other receptors via lowaffinity interactions, such as the receptor-type proteintyrosine phosphatase zeta (PTPRZ1) (12) and syndecan-1 (CD138) (13). These studies indicate that IL-34 may also act different functions independently of the CSD-1R. PTPRZ1 is a constitutively active phosphatase, the activation repressed when binding to IL-34. IL-34 binding to syndecan-1 regulates CSF-1R signaling, and IL-34 induces the migration of macrophages in syndecan-1-dependent manner. Therefore, other receptors may mediate the activities of IL-34, which should be revealed in future studies. IL-34 can stimulate monocyte and macrophage differentiation by secreting pro-inflammatory cytokines, such as IL-6 and TNF- $\alpha$ (14). IL-34 participates in diverse autoimmune and inflammatory diseases, and its role as a novel therapeutic target has been identified. Serum levels of IL-34 are significantly increased in rheumatoid arthritis (RA) patients and correlated with disease severity (15). In addition, the expression of IL-34 is elevated in the serum and intestine of inflammatory bowel disease (IBD) patients (16). Moreover, IL-34 can be detected in adipose tissues, and the concentration of IL-34 is markedly upregulated in obesity patients and highly related to insulin resistance (17).

The molecular factors that regulate $\beta$ cell development and function have not been fully elucidated. The aim of this study was to explore the concentrations of serum and cord blood IL-34 in patients with newly diagnosed GDM and to measure the association between clinical features and IL-34 expression. We also compared the mRNA and protein expression of IL-34 in placentas from GDM patients and healthy pregnant women. In order to investigate the role of IL-34 in the development of GDM, we also evaluated the effect of recombinant mouse IL-34 (rmIL-34) on apoptosis and pancreatic $\beta$ cell function.

\section{Materials and methods}

\section{Study groups}

A cross-section study was performed at the Second Affiliated Hospital of Shenyang Medical University. A total of 120 women were enrolled in this study, which included 60 GDM patients and age- and sex-matched healthy pregnant women. All subjects were enrolled at 24-28 weeks of gestation and admitted to the hospital at term pregnancy. Women diagnosed with GDM earlier during pregnancy, previous overt T1DM or T2DM, taking drug treatment interfering with glucose metabolism or with preeclampsia were excluded from this study. In this study group, patients with GDM received one or two treatments (diet therapy with self-monitoring of glucose or insulin therapy) to maintain blood glucose levels. Insulin therapy was treated when blood glucose levels remained above target levels despite strict diet therapy. The study protocols were approved by the Ethics Committee of Shenyang Medical University (number of the ethical vote $=12$ ). Informed consent was provided by all subjects. All subjects underwent a physical examination, such as detection of weight and height before pregnancy, and BMI before and after gestation were also calculated. The homeostasis model assessment for insulin resistance 
(HOMA-IR) was calculated by the following equation: HOMA-IR =fasting glucose $(\mathrm{mmol} / \mathrm{L}) \times$ fasting insulin $(\mu \mathrm{IU} / \mathrm{mL}) / 22.5$. Women from the study group during weeks 24-28 of pregnancy were given a 75-g OGTT. The patients were diagnosed with GDM in response to the criteria of the American Diabetes Association (18): fasting plasma glucose $(\mathrm{FPG}) \geq 5.1 \mathrm{mmol} / \mathrm{L}, 1 \mathrm{~h} \geq 10.0 \mathrm{mmol} / \mathrm{L}$, or $2 \mathrm{~h} \geq 8.5 \mathrm{mmol} / \mathrm{L}$. The maternal and cord blood were centrifuged, collected and stored at $-80^{\circ} \mathrm{C}$ until analysis. During delivery, immediately after removal of the placenta, samples $(2 \times 1 \times 1 \mathrm{~cm})$ were collected from the central part of the placenta. The placentas from the two groups were stored at $-80^{\circ} \mathrm{C}$ until further use.

\section{Serum and cord blood IL-34 concentrations}

Serum and cord blood IL-34 levels were analysed by ELISA (R\&D Systems). In general, plates coated with IL-34 antibody were cultured with five-fold of thinned serum at room temperature for $2 \mathrm{~h}$. The plates were washed and further incubated for $2 \mathrm{~h}$ with horseradish peroxidaseconjugated IL-34 antibody. The plates were then washed, treated with tetramethylbenzidine and incubated for 30 min. Ultimately, sulphuric acid was added to end the reaction. The absorbance at $450 \mathrm{~nm}$ was detected. The intra-assay $\mathrm{CV}$ was $<10 \%$ and the inter-CV was $<6 \%$.

\section{Western blot analysis}

Proteins from placental tissues were homogenized in ice cold PBS containing $0.05 \%$ Triton X-100 and protease inhibitor cocktail (Sigma-Aldrich). Protein samples were run on 10\% SDS-PAGE (Sigma) and transferred onto PVDF membranes according to standard protocol and then blocked with 5\% dried skimmed milk in TBST for at least $1 \mathrm{~h}$. The membranes were then incubated overnight at $4^{\circ} \mathrm{C}$, either with anti-IL-34 or STAT3 antibodies $(1: 1000$, Abcam), anti-CSF-1R, p-STAT3, anti-cleaved-caspase 3 and caspase- 3 antibodies (1:1000, Cell Signaling) or anti-GAPDH (1:1000, Abcam), and then incubated with horseradish peroxidase-conjugated secondary antibodies (1:1000, Abcam) at room temperature for $1 \mathrm{~h}$ after washing three times using TBST. Blots were washed again and developed using an enhanced chemiluminescence kit (Amersham Pharmacia Biotech). Immunoblot band quantification was calculated by means of a Bio-Rad calibrated densitometer (GS-800) using the vendor's software (Bio-Rad Laboratories); GAPDH was used as an internal reference for analyses.

\section{Quantitative real-time PCR analysis}

Total RNA was extracted from placental samples using TRIzol (Invitrogen; Thermo Fisher Scientific). RT was achieved using a Takara Kit (TaKaRa Biotechnology). cDNA amplification was then performed using SYBR Premix Ex Taq (TaKaRa) in a Roche 480 Light Cycler. PCR was carried out for 40 cycles according to the following procedure: $95^{\circ} \mathrm{C}$ for $30 \mathrm{~s}$, annealing for $30 \mathrm{~s}$, and $60^{\circ} \mathrm{C}$ for $34 \mathrm{~s}$. Each sample was analysed in duplicate. The relative mRNA expression levels of the target genes were calculated with the $2^{-\Delta \mathrm{Ct}}$ method after normalization to GAPDH. The mRNA sequences used for PCR were as follows: IL-34, 5'-TTGACGCAGAATGAGGAGTG-3' (forward); 5'-CCCTCGTAAGGCACACTGAT-3' (reverse); GAPDH， 5'-CAGGAGGCATTGCTGATGAT-3' (forward); 5'-GAAGGCTGGGGCTCATTT-3' (reverse).

\section{Cell culture and treatment}

Mouse pancreatic $\beta$ cells (MIN6) were purchased from the American Type Culture Collection. MIN6 cells were cultured in Dulbecco's modified Eagle's medium (DMEM, Gibco) supplemented with 10\% foetal bovine serum (FBS, Hyclone), $100 \mathrm{U} / \mathrm{mL}$ penicillin (Gibco) and $100 \mathrm{~g} / \mathrm{mL}$ streptomycin (Gibco). All cells were cultured under a $5 \% \mathrm{CO}_{2}$ atmosphere at $37^{\circ} \mathrm{C}$. The medium was changed 2 days and cultured when the cell population density reached $70-80 \%$ confluence. Different concentrations of recombinant rhIL-34 (from 0 to $50 \mathrm{ng} / \mathrm{mL}$; R\&D Systems) were used to study downstream signalling transduction factors. MIN6 cells were also treated with rhIL-34 $(50 \mathrm{ng} / \mathrm{mL})$ alone or co-stimulated with CSF-1R inhibitor (25 $\mu \mathrm{M}$; Tocris Cookson, Bristol, UK) for $24 \mathrm{~h}$. The cells were collected for further analysis.

\section{Cell viability}

The MTT assay was used to determine the cell viability. MIN6 cells were seeded at $1 \times 10^{3}$ cells/well in 96-well plates. After the cells were cultured for 3 days, the media were rinsed twice with sterile phosphate buffered saline (PBS), and the adherent cells were incubated in medium containing $100 \mathrm{mg} / 0.1 \mathrm{~mL}$ MTT (Sigma-Aldrich) for $4 \mathrm{~h}$. After carefully removing the medium, the water-insoluble purple crystal layer was dissolved using DMSO. The optical density (OD) was measured at $595 \mathrm{~nm}$ using a spectrophotometer.

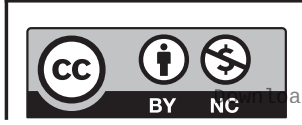

This work is licensed under a Creative Commons Attribution-NonCommercial 4.0 International License. ded from Bioscientifica.com at 04/26/2023 10:40:13AM 


\section{Insulin secretion measurement}

MIN6 cells were treated with normal glucose $(3.3 \mathrm{mM})$ or high glucose medium $(16.7 \mathrm{mM})$ for $1 \mathrm{~h}$. Total insulin secretion was analysed after transonic treatment three times and centrifuged for $10 \mathrm{~min}$ at $12,000 \mathrm{~g}$. The concentrations of insulin were detected by ELISA according to the manufacturer's instructions.

\section{Flow cytometry analysis of apoptosis}

The rates of apoptosis for MIN6 cells were analysed using an Annexin V and PI Detection Kit (BD Pharmingen, San Jose, CA, USA) according to the manufacturer's instructions. Samples were then analysed with a BD FACS Array (Becton-Dickinson) using Cell quest software.

\section{Statistical analysis}

All statistical analyses were performed using SPSS Software 20.0 (SPSS). The results are given as the means \pm s.D. A $t$ test was used to compare the differences between GDM and healthy pregnant women. Spearman's method was used for the correlation analysis between IL-34 concentrations and clinical characteristics. GraphPad Prism 5 software was used to analyse the data and create graphs. $P$ values $<0.05$ were viewed as statistically significant.

\section{Results}

\section{Clinical data}

A total of 120 pregnant women were enrolled in our study, which included 60 patients with newly diagnosed GDM and 60 age- and sex-matched controls. The clinical features of the study group are presented in Table 1. Fasting blood glucose and insulin concentrations were significantly increased in the GDM group $(P<0.05$, respectively). HOMA-IR was also significantly higher in GDM patients than that in healthy pregnant women $(P<0.05)$. In cord blood, glucose levels in GDM patients were significantly higher than those in healthy controls $(P<0.05)$. Moreover, insulin concentrations were uniformly higher in cord blood from GDM patients than those from healthy pregnant women $(P<0.05)$. We also found that HOMA-IR in cord blood was markedly increased in GDM patients $(P<0.05)$. No significant differences in systolic and diastolic blood pressure were found between the two groups. There were no significant differences regarding maternal and gestational age, BMI, systolic and diastolic

blood pressure and foetal weight between GDM patients and controls $(P>0.05)$.

\section{Maternal and cord blood IL-34 was upregulated in GDM patients}

IL-34 expression was examined in the maternal and cord blood of GDM patients and healthy pregnant women. As displayed in Fig. 1A, the serum levels of IL-34 were significantly increased in GDM patients $(342.2 \pm 64.1)$ compared to those in healthy controls $(148.5 \pm 30.5$, $P<0.05)$. Moreover, IL-34 levels in cord blood were also significantly higher in mothers with GDM $(83.1 \pm 6.3)$ compared with levels in healthy individuals (Fig. 1B, $48.4 \pm 5.2, P<0.05)$.

GDM patients were divided into two subgroups due to the different treatment as patients administrated with insulin therapy $(n=24)$ and patients self-monitored with diet $(n=36)$ for further investigation. As presented in Fig. $1 \mathrm{C}$, there is no significant difference between diet group $(347 \pm 58.0)$ and insulin group $(335 \pm 73.6, P>0.05)$.

\section{Association between laboratory parameters and IL-34 levels from maternal and cord blood in GDM patients}

In this study, we also analysed the association between the clinical and laboratory characteristics and the expression of IL-34. We analysed the correlation IL-34 concentrations in mother and offspring of the control group and found a significant positive correlation $(r=0.5746, P<0.001$, Fig. 1D).

Table 1 The clinical characteristics of patients with GDM and healthy controls during pregnancy.

\section{Variabies}

Maternal age (years)

Gestational age (weeks)

Fasting glucose $(\mathrm{mmol} / \mathrm{L})$

Fasting insulin ( $\mathrm{mU} / \mathrm{L})$

HOMA-IR

Cord blood glucose $(\mathrm{mmol} / \mathrm{L})$

Cord blood insulin ( $\mathrm{mU} / \mathrm{L})$

Cord blood HOMA-IR

BMI before pregnancy $\left(\mathrm{kg} / \mathrm{m}^{2}\right)$

$\mathrm{BMI}$ at delivery $\left(\mathrm{kg} / \mathrm{m}^{2}\right)$

Systolic pressure $(\mathrm{mmHg})$

Diastolic pressure $(\mathrm{mmHg})$

Offspring weight $(\mathrm{g})$

Offspring sex (males/females)

Placental weight ( $g$ )

\begin{tabular}{cccc}
\hline GDM $(n=60)$ & & Controls $(n=60)$ \\
\cline { 1 - 1 } $30.3 \pm 4.3$ & & $31.0 \pm 4.7$ \\
$36.3 \pm 4.2$ & & $36.4 \pm 5.22$ \\
$5.6 \pm 0.4$ & & $4.2 \pm 0.2^{\mathrm{a}}$ \\
$10.4 \pm 0.4$ & & $9.0 \pm 0.2^{\mathrm{a}}$ \\
$2.6 \pm 0.2$ & & $1.7 \pm 0.1^{\mathrm{a}}$ \\
$4.1 \pm 0.2$ & & $3.5 \pm 0.1^{\mathrm{a}}$ \\
$6.7 \pm 0.3$ & & $5.1 \pm 0.2^{\mathrm{a}}$ \\
$1.2 \pm 0.06$ & & $0.8 \pm 0.04^{\mathrm{a}}$ \\
$21.6 \pm 2.2$ & & $20.9 \pm 4.0$ \\
$29.9 \pm 4.1$ & & $28.4 \pm 2.4$ \\
$126 \pm 6$ & & $121 \pm 7$ \\
$80 \pm 5$ & & $78 \pm 6$ \\
$3528 \pm 98$ & & $3498 \pm 87$ \\
$32 / 28$ & & $26 / 34$ \\
$534.5 \pm 43$ & & $582.7 \pm 65$ \\
& &
\end{tabular}

Data are expressed as mean \pm S.D. according to the distribution awas considered significant.

BMI, body mass index; GDM, gestational diabetes mellitus.

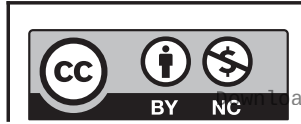


A
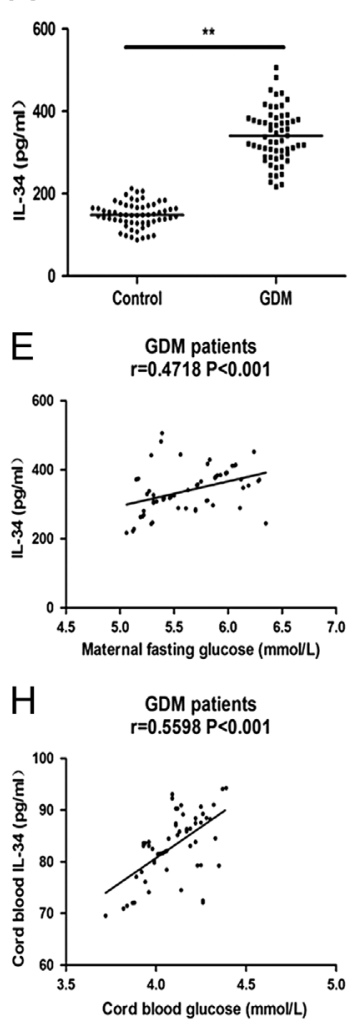

B
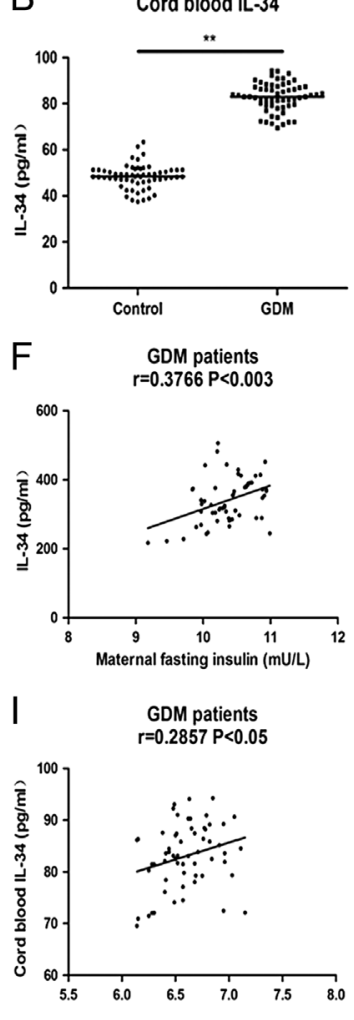

C

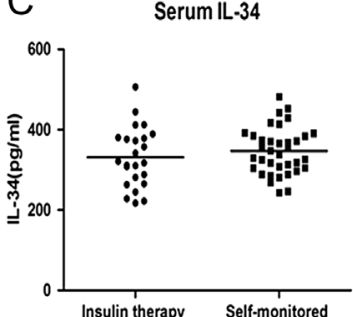

G GDM patients
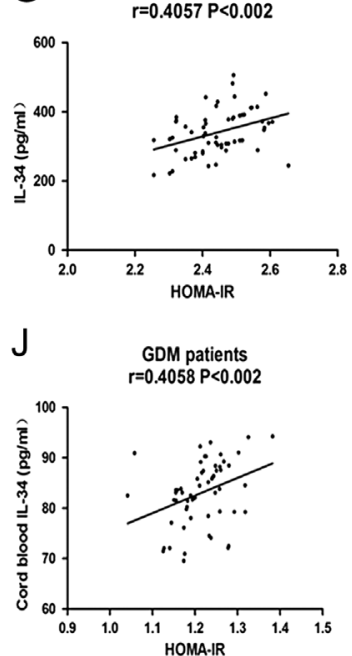

D Control subjects $r=0.5746 \mathrm{P}<0.001$

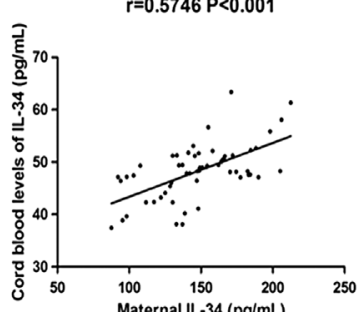

Maternal IL-34 (pg/mL)

\section{Figure 1}

Serum and cord blood IL-34 expression and correlation analysis with laboratory parameters in patients with gestational diabetes mellitus (GDM) and healthy pregnancy controls. Dot plots showing the serum levels of IL-34 in maternal (A) and cord blood (B) in patients with GDM and controls. (C) Dot plots showing the serum levels of IL-34 in GDM patients administrated with insulin therapy and patients self-monitored with diet. IL-34 concentrations were analyzed by ELISA. (D) Scatter plots presenting the correlation between maternal IL-34 concentrations versus cord blood IL-34 levels in control subjects. Scatter plots presenting the correlation between maternal IL-34 concentrations versus (E) fasting glucose, (F) fasting insulin, (G) maternal HOMA-IR at delivery and the relationship between cord blood IL-34 levels versus (H) cord blood glucose (I) cord blood insulin (U) cord blood HOMA-IR in GDM patients. The correlation between IL-34 and clinical characteristic was analyzed with Spearman's method. ** $P<0.01$ was considered significant.

As shown in Fig. 1E, a positive correlation between maternal IL-34 concentrations and fasting glucose levels was found in GDM patients $(r=0.4718, P<0.001)$. Serum IL-34 levels were also positively associated with fasting insulin and HOMA-IR (Fig. $1 \mathrm{~F}$ and $\mathrm{G}, r=0.3766, P<0.003$; $r=0.4057, P<0.002$, respectively). We also analysed the correlation between cord blood levels of IL-34 and the clinical parameters of GDM patients. As shown in Fig. 1H, the levels of IL-34 in cord blood were positively associated with cord blood glucose levels in the GDM group $(r=0.5598, \quad P<0.001)$. Moreover, IL-34 concentrations were also positively correlated with insulin levels and HOMA-IR in cord blood from GDM patients (Fig. 1I and J, $r=0.2857, P<0.05 ; r=0.4058, P<0.002$, respectively).

\section{Placental IL-34 mRNA and protein expression}

The expression of placental IL-34 mRNA was significantly increased in the placenta from GDM women compared to that from healthy pregnant women (Fig. $2 \mathrm{~A}, P<0.05$ ). In addition, as shown in Fig. 2B, IL-34 placental expression in GDM patients was also significantly higher than that in healthy subjects $(P<0.05)$.

\section{CSF-1R is involved in IL-34-dependent STAT3 activation}

As presented in Fig. 3A, B, C and D, IL-34 supplementation significantly elevated CSF-1R and p-STAT3 expression in a dose-dependent manner in MIN6 cells $(p<0.05)$. These results indicated that IL-34 treatment regulates STAT3 activation in combination with CSF-1R.

\section{High glucose induced an increase in IL-34 expression in MIN6 cells}

As shown in Fig. 3E, IL-34 expression was elevated when MIN6 cells were treated with high glucose,

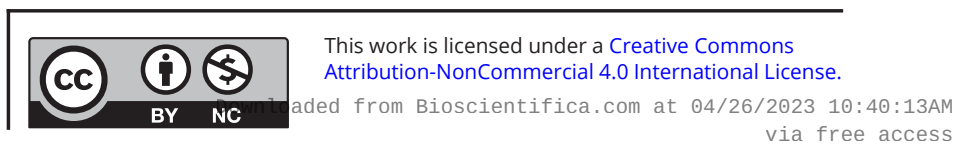


A
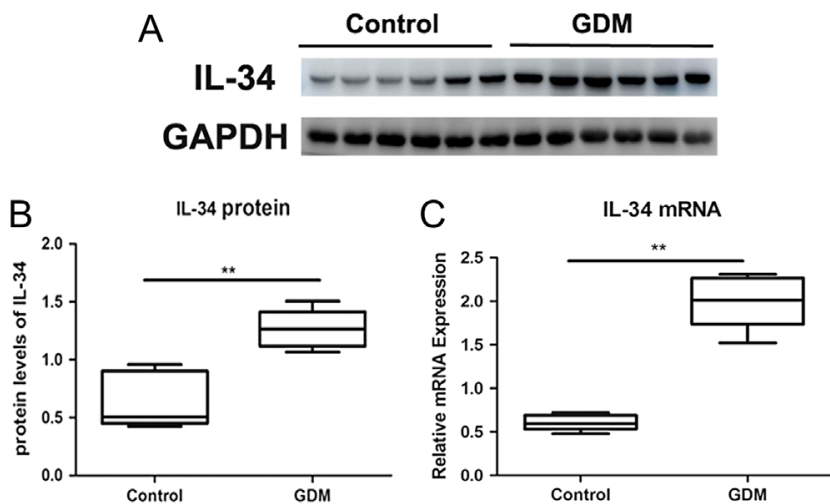

Figure 2

Protein and mRNA expression of IL-34 from the placental tissues in gestational diabetes mellitus (GDM) patients and controls. (A) Western blot analysis of IL-34 expression in placental tissues from GDM and controls. (B) The ratio of IL-34/GAPDH was determined to give a mean net density. (C) IL-34 mRNA expression was examined by real-time PCR using GAPDH as an endogenous reference. Data are presented as the means \pm S.E. ${ }^{*} P P<0.01$ was considered significant.

and IL-34 protein expression was significantly higher in the high glucose-treated group than that in the untreated group $(P<0.05)$.

\section{The IL-34/CSF-1R/STAT3 axis contributes to the apoptosis and function of pancreatic $\beta$ cells}

To determine whether IL-34 contributes to the function of pancreatic $\beta$ cells, we performed studies on IL-34treated MIN6 cells. As shown in Fig. 4A, IL-34 decreased cell viability, whereas the CSF-1R inhibitor upregulated the role of IL-34 on reactivity $(P<0.05)$. We discovered that insulin secretion was reduced in cells treated with IL-34, while the reduction was blocked upon inhibition of CSF-1R (Fig. 4B, $P<0.05$ ). High glucose levels can cause insulin production. However, our results showed that IL-34 overexpression could reduce insulin secretion under either low or high glucose conditions, while the effect was hampered by supplementing MIN6 cells with CSF-1R inhibitor (Fig. 4C, $P<0.05$ ). To further analyse whether IL-34 contributes to cell apoptosis, we measured the apoptotic rates by flow cytometry. As demonstrated in Fig. 4D, cell apoptotic rates were significantly increased in IL-34 overexpressing cells. Upon IL-34 supplementation, the protein expression of cleaved caspase- 3 and p-STAT3 increased. Reduced protein levels, including p-STAT3 and cleaved-caspase-3, were detected with CSF-1R inhibition (Fig. $4 \mathrm{E}, P<0.05$ ), which indicated that the IL-34/CSF-1R/ STAT3 pathway contributes to the apoptosis and function of pancreatic $\beta$ cells.

\section{Discussion}

Our results demonstrated for the first time that IL-34 was elevated in placenta, serum and cord blood in GDM patients. The concentrations of IL-34 were positively associated with the blood glucose levels and insulin resistance in either maternal or cord blood from GDM patients. Overexpressing IL-34 inhibited pancreatic $\beta$ cell function and cell viability. In addition, IL-34 also enhanced the apoptosis of pancreatic $\beta$ cells. These effects of IL-34 can be blocked by a CSF-1R inhibitor.
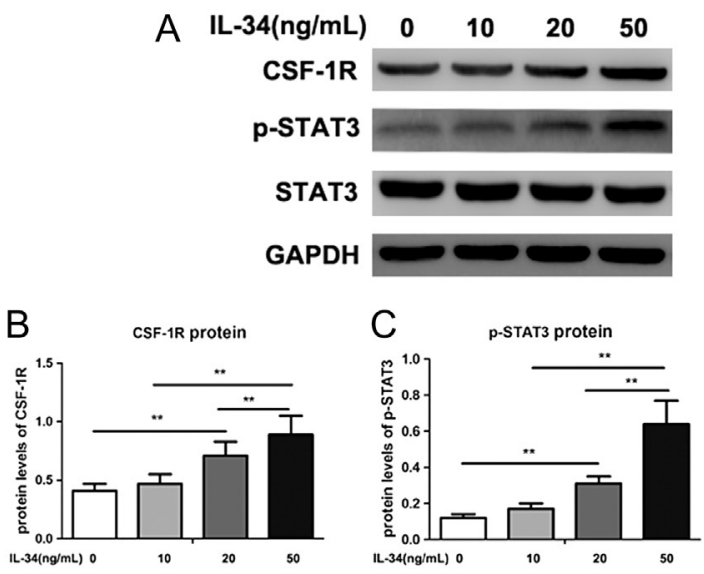

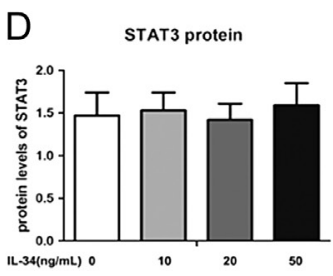

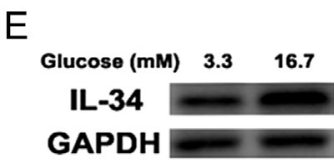

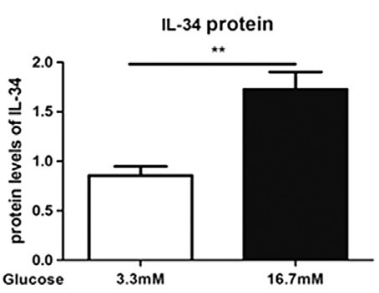

Figure 3

Protein expression of IL-34 in pancreatic $\beta$ cells cultured in the treatment of high glucose and CSF-1R contributes to the biological activities of IL-34. (A) The protein expression levels of CSF-1R and pSTAT3/STAT3 were measured by Western blotting. The ratios of CSF-1R/GAPDH (B), p-STAT3/GAPDH (C) and STAT3/GAPDH (D) were determined to give a mean net density. Protein expression of IL-34 in MIN6 cells cultured as exposure to elevating doses of glucose. (E) The protein expression levels of IL-34 were measured by Western blotting and a representative result is presented. Data are presented as the means \pm S.E. ${ }^{* *} P<0.01$ was considered significant.

https://ec.bioscientifica.com

https://doi.org/10.1530/EC-19-0436 (c) 2019 The authors Published by Bioscientifica Ltd

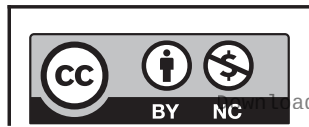

This work is licensed under a Creative Commons Attribution-NonCommercial 4.0 International License. ded from Bioscientifica.com at 04/26/2023 10:40:13AM 

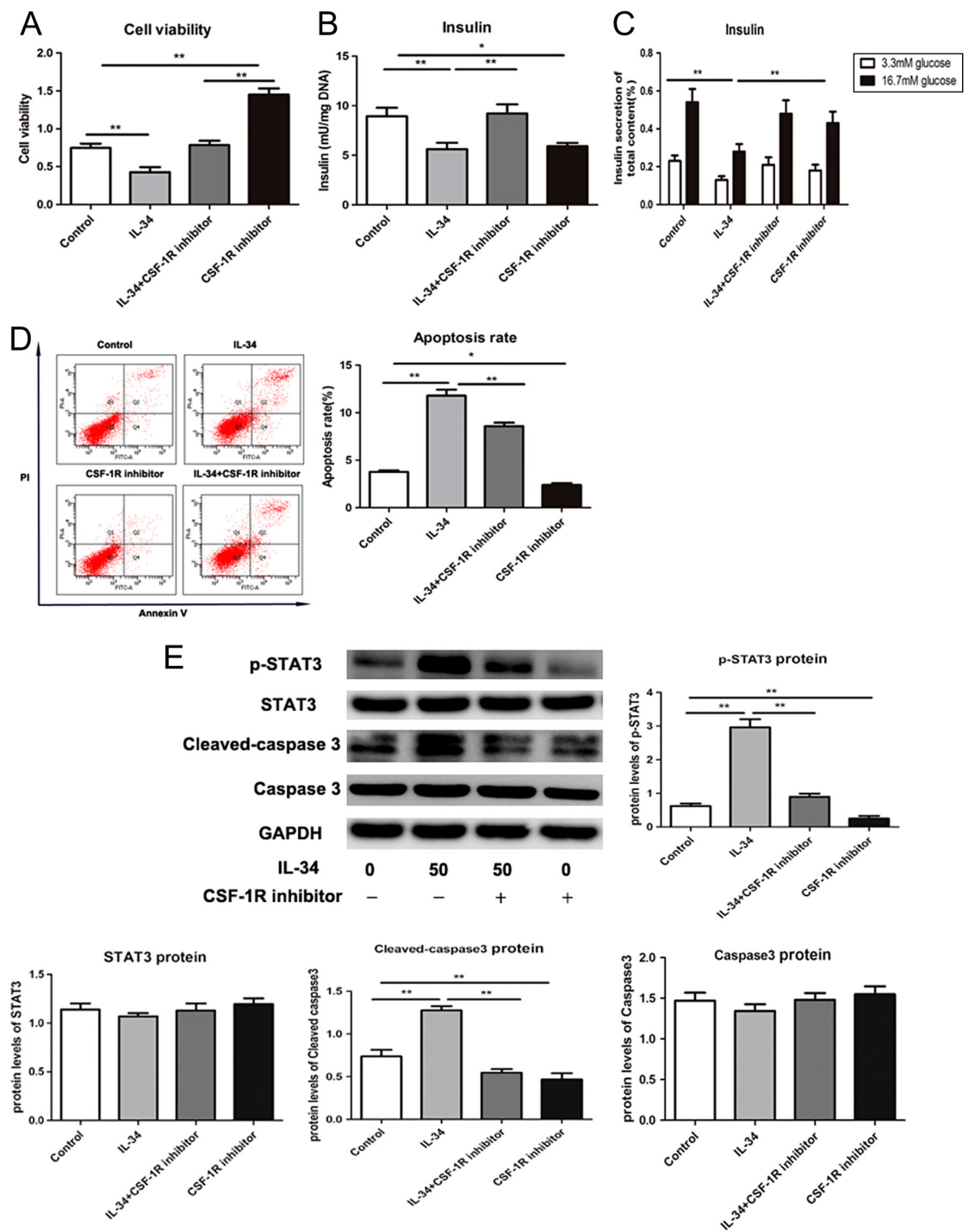

Figure 4

IL-34 inhibits the function of pancreatic $\beta$ cells and enhance apoptosis by targeting CSF-1R. Total insulin content (B) and insulin secretion (C) was analysed by ELISA assay. (A) Cell viability was measured by MTT assay. (D) Cell apoptosis was determined by flow cytometry and the apoptotic rates are shown. (E) The protein expression levels of p-STAT3/STAT3 and cleaved caspase 3/caspase 3 were measured by Western blotting and a representative result is presented. Data are presented as the means \pm S.E. $* * P<0.01$ was considered significant.
Although multiple studies focused on the pathogenesis of GDM, the mechanism has not been fully understood. GDM has been regarded as one of the most common metabolic complications during gestation, with a morbidity of above 20\% (3). Among all the influencing factors, inflammatory cytokines play a vital role in the pathogenesis of GDM. Accumulating studies have reported the relationship between the inflammatory state and obstetric diseases (19), with some demonstrating the association between pro-inflammatory cytokines and GDM (20), yet none are related to IL-34. In our study, we found that maternal and cord blood IL-34 levels were markedly increased in GDM patients compared with healthy pregnant women. Moreover, the IL-34 concentration was positively associated with glucose, and its levels were also correlated with HOMA-IR and insulin concentrations. To the best of our knowledge, this is the first report to evaluate IL-34 levels in GDM patients. A SNP of IL-34 is related to T2DM according to genomic study and meta-analysis results (21), which suggests a possible role of IL-34 in diabetes-related disease. In a cohort study, Chang et al. found a vital role of IL-34 in obesity patients, which demonstrated that serum IL-34 levels were upregulated in obese women and significantly correlated with the metabolic index and insulin resistance (17). Insulin resistance has been demonstrated to be a crucial factor of GDM. Overexpression of inflammatory cytokines has been suggested to regulate insulin resistance and accelerate inflammation in GDM, and serum levels of cytokines, including TNF- $\alpha$ and IL- 6 , have been found to be upregulated in GDM patients $(22,23)$. Moreover, IL-34 may directly participate in the development of insulin resistance, as demonstrated by the finding that IL-34 treatment markedly reduced insulin-induced glucose 
transport in differentiated adipocytes (17). In this study, we also analysed the correlation IL-34 concentrations in mother and offspring of the control group, and found a significant positive correlation. This result indicated that IL-34 could be secreted into the foetal circulation and directly affect foetal metabolism. The role of IL-34 in inflammation has been documented that showed promoted expression of IL-34 in different kinds of cells through exposure to multiple inflammatory molecules that stimulate NF-кB signalling pathway $(14,24)$. Since NF- $\mathrm{kB}$ is a key regulator of inflammatory signalling pathway, IL-34 is considered to be related to a series of inflammatory diseases. IL-34 can also induce the expression of pro-inflammatory cytokines such as TNF$\alpha$ and IL-6. Therefore, IL-34 is suggested to regulate a positive feedback loop that leads to amplification of the inflammatory circulation $(16,25)$. Our results also showed that cord blood IL-34 levels were positively associated with cord HOMA-IR, which indicated that IL-34 could be a vital biomarker of intrauterine hyperglycaemia and a predictor of insulin dysfunction in the foetus of patients with GDM. Bush et al. discovered that maternal hyperglycaemia is positively associated with insulin resistance and pancreatic $\beta$ cell function, which suggests that intrauterine hyperglycaemia contributes to the dysfunctional $\beta$ cell secretion and insulin target organs (26). The present study demonstrated that cord blood IL-34 levels from GDM patients were markedly elevated, indicating that intrauterine hyperglycaemia may accelerate placental IL-34 production. These results suggest that IL-34 contributes to the development of GDM, which makes it a potential biomarker for GDM diagnosis.

Although IL-34 is widely detected in multiple tissues, its expression in the placenta was not fully elucidated until this study. We found that IL-34 mRNA and protein expression is highly increased in the placenta of GDM patients. This result was in accordance with the study by Chang et al. who reported that IL-34 mRNA was highly elevated during adipogenesis (17). Our findings suggest that IL-34 may contribute to the regulation of local inflammation, reacting to the elevated inflammatory state in placental tissues during GDM conditions. The placenta is a transient organ and functions as a link between mother and foetus. It plays a vital role during entire pregnancy, regulating the alternative exchange of nutrients across foetal-maternal interface. Maternal hyperglycaemia modifies placenta morphometric features, changes the structural integrity of syncytiotrophoblasts, and induces major alternations in the expression of chronic inflammation and stress in placenta (27). Increased biomarkers of maternal inflammation have been reported in GDM patients (28). Macrophages, the primary cells in healthy placenta, are likely to be affected by $\operatorname{GDM}(29,30)$. Lindau et al. found for the first time that IL-34 is presented at the foetal-maternal interface and has the ability to induce decidual macrophages (31). IL-34 has been demonstrated to be contributed to the mediation of some tissue-resident macrophage subsets, and has been considered as a potential macrophage-regulating factor. This evidence supports a regulatory role of IL-34 in the GDM placenta throughout pregnancy.

Since there is an association between glucose levels and IL-34, we treated mouse pancreatic $\beta$ cells (MIN6) with high glucose, and the effect of glucose enhancement on IL-34 expression in MIN6 cells was found. We also studied the effect of IL-34 on the function of pancreatic $\beta$ cells. Overexpression of IL-34 inhibited the insulin secretion and cell viability of pancreatic $\beta$ cells. IL-34 may participate in the development of insulin resistant in target cell, as indicated by our results that IL-34 was participated in insulin-caused glucose transport (17). Apoptosis plays a vital role in GDM. Elevated pancreatic $\beta$ cell apoptosis has been found in patients with GDM. In response to supplementation with IL-34, the apoptotic rate of MIN6 cells was significantly increased. Moreover, cleaved-caspase-3 expression was also upregulated with IL-34 stimulation. In addition, we also found that IL-34 can regulate the phosphorylation of STAT3 via CSF-1R, and the expression of p-STAT3 was enhanced with increasing IL-34 concentrations. Our results indicated that IL-34 promotes STAT3 phosphorylation by CSF-1R, consequently accelerating the apoptosis of pancreatic $\beta$ cells in GDM patients.

Although this study was the first report to investigate the potential role of IL-34 in GDM patients, some limitations must be demonstrated. First of all, the crosssectional study indicated that it was not able to investigate if there was an association between IL-34 and the process of GDM. Second, the sample size was small which might mask the weak relationship between IL-34 concentrations and offspring characteristics. Third, we did not study the expression of other pro-inflammatory cytokines and the correlation between IL-34 and major cytokines of GDM. We cannot presume that GDM was directly linked to IL-34. In addition, the gestational data from OGTT at 24 to 28 weeks may not directly indicate the glycaemic status during the whole gestation. Besides, the maternal glucose levels in the long run and the offspring consequences are uncertain and in this study we can't make conclusions

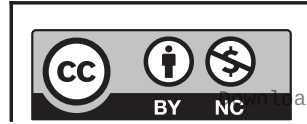

This work is licensed under a Creative Commons Attribution-NonCommercial 4.0 International License. ded from Bioscientifica.com at 04/26/2023 10:40:13AM 
due to the cross-sectional study and lack of entire inflammatory status. Fourth, other receptors may mediate the activities of IL-34, which should be revealed in future studies. Further studies are needed to confirm these results.

\section{Conclusion}

We found that maternal and cord blood IL-34 concentrations were elevated in GDM patients and the levels were positively associated with maternal and cord blood HOMA-IR. IL-34 enhances apoptosis while inhibiting cell viability and pancreatic $\beta$ cell function by CSF-1R. This study reveals that IL-34 may be a potential biomarker in patients with GDM. Further studies are needed to explore the pathogenesis of the alternation of IL-34 in vivo.

\section{Declaration of interest}

The authors declare that there is no conflict of interest that could be perceived as prejudicing the impartiality of the research reported.

\section{Funding}

This work is supported by the Natural Science Foundation of Liaoning Province (grant numbers 20170520040), Program of Science Technology Foundation of Liaoning Province (grant numbers 2017225061), the Natural Science Funding (grant numbers 81702738), and the Scientific Program for Doctoral Initial Funding (grant 201501042)

\section{References}

1 Guillen-Sacoto MA, Barquiel B, Hillman N, Burgos MÁ \& Herranz L. Gestational diabetes mellitus: glycemic control during pregnancy and neonatal outcomes of twin and singleton pregnancies. Endocrinologia, Diabetes y Nutricion 201865 319-327. (https://doi. org/10.1016/j.endinu.2018.01.011)

2 Diagnostic criteria and classification of hyperglycaemia first detected in pregnancy: a World Health Organization Guideline. Diabetes Research and Clinical Practice 2014103 341-363. (https://doi. org/10.1016/j.diabres.2013.10.012)

3 Sacks DA, Hadden DR, Maresh M, Deerochanawong C, Dyer AR, Metzger BE, Lowe LP, Coustan DR, Hod M, Oats JJ, et al. Frequency of gestational diabetes mellitus at collaborating centers based on IADPSG consensus panel-recommended criteria: the Hyperglycemia and Adverse Pregnancy Outcome (HAPO) Study. Diabetes Care 2012 35 526-528. (https://doi.org/10.2337/dc11-1641)

4 Dabelea D. The predisposition to obesity and diabetes in offspring of diabetic mothers. Diabetes Care 200730 (Supplement 2) S169-S174. (https://doi.org/10.2337/dc07-s211)

5 Catalano PM. Trying to understand gestational diabetes. Diabetic Medicine 201431 273-281. (https://doi.org/10.1111/dme.12381)

6 Zhang H, Zhang J, Pope CF, Crawford LA, Vasavada RC, Jagasia SM \& Gannon M. Gestational diabetes mellitus resulting from impaired beta-cell compensation in the absence of FoxM1, a novel downstream effector of placental lactogen. Diabetes 201059 143-152. (https://doi.org/10.2337/db09-0050)
7 Buchanan TA. Pancreatic B-cell defects in gestational diabetes: implications for the pathogenesis and prevention of type 2 diabetes. Journal of Clinical Endocrinology and Metabolism 200186 989-993. (https://doi.org/10.1210/jcem.86.3.7339)

8 Pantham P, Aye IL \& Powell TL. Inflammation in maternal obesity and gestational diabetes mellitus. Placenta 201536 709-715. (https:// doi.org/10.1016/j.placenta.2015.04.006)

9 Kolb H \& Mandrup-Poulsen T. An immune origin of type 2 diabetes? Diabetologia 200548 1038-1050. (https://doi.org/10.1007/s00125005-1764-9)

10 Lin H, Lee E, Hestir K, Leo C, Huang M, Bosch E, Halenbeck R, Wu G, Zhou A, Behrens D, et al. Discovery of a cytokine and its receptor by functional screening of the extracellular proteome. Science $2008 \mathbf{3 2 0}$ 807-811. (https://doi.org/10.1126/science.1154370)

11 Segaliny AI, Brion R, Brulin B, Maillasson M, Charrier C, Teletchea S \& Heymann D. IL-34 and M-CSF form a novel heteromeric cytokine and regulate the M-CSF receptor activation and localization. Cytokine 201576 170-181. (https://doi.org/10.1016/j.cyto.2015.05.029)

12 Nandi S, Cioce M, Yeung YG, Nieves E, Tesfa L, Lin H, Hsu AW, Halenbeck R, Cheng HY, Gokhan S, et al. Receptor-type proteintyrosine phosphatase zeta is a functional receptor for interleukin-34. Journal of Biological Chemistry 2013288 21972-21986. (https://doi. org/10.1074/jbc.M112.442731)

13 Segaliny AI, Brion R, Mortier E, Maillasson M, Cherel M, Jacques Y, Le Goff B \& Heymann D. Syndecan-1 regulates the biological activities of interleukin-34. Biochimica et Biophysica Acta 20151853 1010-1021. (https://doi.org/10.1016/j.bbamcr.2015.01.023)

14 Guillonneau C, Bezie S \& Anegon I. Immunoregulatory properties of the cytokine IL-34. Cellular and Molecular Life Sciences 201774 2569-2586. (https://doi.org/10.1007/s00018-017-2482-4)

15 Moon SJ, Hong YS, Ju JH, Kwok SK, Park SH \& Min JK. Increased levels of interleukin 34 in serum and synovial fluid are associated with rheumatoid factor and anticyclic citrullinated peptide antibody titers in patients with rheumatoid arthritis. Journal of Rheumatology 201340 1842-1849. (https://doi.org/10.3899/jrheum.130356)

16 Zwicker S, Martinez GL, Bosma M, Gerling M, Clark R, Majster M, Soderman J, Almer S \& Bostrom EA. Interleukin 34: a new modulator of human and experimental inflammatory bowel disease. Clinical Science 2015129 281-290. (https://doi.org/10.1042/CS20150176)

17 Chang EJ, Lee SK, Song YS, Jang YJ, Park HS, Hong JP, Ko AR, Kim DY, Kim JH, Lee YJ, et al. IL-34 is associated with obesity, chronic inflammation, and insulin resistance. Journal of Clinical Endocrinology and Metabolism 201499 E1263-E1271. (https://doi.org/10.1210/ jc.2013-4409)

18 Davies MJ, D'Alessio DA, Fradkin J, Kernan WN, Mathieu C, Mingrone G, Rossing P, Tsapas A, Wexler DJ \& Buse JB. Management of hyperglycemia in Type 2 diabetes, 2018. A Consensus Report by the American Diabetes Association (ADA) and the European Association for the Study of Diabetes (EASD). Diabetes Care 201841 2669-2701. (https://doi.org/10.2337/dci18-0033)

19 Nadeau-Vallee M, Obari D, Palacios J, Brien MÈ, Duval C, Chemtob S \& Girard S. Sterile inflammation and pregnancy complications: a review. Reproduction 2016152 R277-R292. (https://doi.org/10.1530/ REP-16-0453)

20 Skorzynska-Dziduszko KE, Kimber-Trojnar Ż, Patro-Malysza J, Olszewska A, Zaborowski T \& Malecka-Massalska T. An interplay between obesity and inflammation in gestational diabetes mellitus. Current Pharmaceutical Biotechnology 201617 603-613. (https://doi. org/10.2174/1389201017666160127105926)

21 Below JE, Gamazon ER, Morrison JV, Konkashbaev A, Pluzhnikov A, McKeigue PM, Parra EJ, Elbein SC, Hallman DM, Nicolae DL, et al. Genome-wide association and meta-analysis in populations from Starr County, Texas, and Mexico City identify type 2 diabetes susceptibility loci and enrichment for expression quantitative trait loci in top signals. Diabetologia 201154 2047-2055. (https://doi org/10.1007/s00125-011-2188-3)

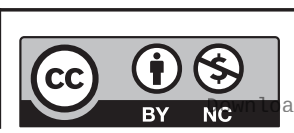

This work is licensed under a Creative Commons Attribution-NonCommercial 4.0 International License. ded from Bioscientifica.com at 04/26/2023 10:40:13AM 
22 Kirwan JP, Hauguel-De Mouzon S, Lepercq J, Challier JC, HustonPresley L, Friedman JE, Kalhan SC \& Catalano PM. TNF-alpha is a predictor of insulin resistance in human pregnancy. Diabetes 200251 2207-2213. (https://doi.org/10.2337/diabetes.51.7.2207)

23 Nergiz S, Altinkaya ÖS, Kucuk M, Yuksel H, Sezer SD, Kurt Omurlu İ \& Odabasi AR. Circulating galanin and IL-6 concentrations in gestational diabetes mellitus. Gynecological Endocrinology 201430 236-240. (https://doi.org/10.3109/09513590.2013.871519)

24 Baghdadi M, Endo H, Tanaka Y, Wada H \& Seino KI. Interleukin 34, from pathogenesis to clinical applications. Cytokine 201799 139-147. (https://doi.org/10.1016/j.cyto.2017.08.020)

25 Franze E, Monteleone I, Cupi ML, Mancia P, Caprioli F, Marafini I, Colantoni A, Ortenzi A, Laudisi F, Sica G, et al. Interleukin-34 sustains inflammatory pathways in the gut. Clinical Science 2015129 271-280. (https://doi.org/10.1042/CS20150132)

26 Matthews DR, Hosker JP, Rudenski AS, Naylor BA, Treacher DF \& Turner RC. Homeostasis model assessment: insulin resistance and beta-cell function from fasting plasma glucose and insulin concentrations in man. Diabetologia 198528 412-419. (https://doi. org/10.1007/bf00280883)

27 Calderon IM, Damasceno DC, Amorin RL, Costa RA, Brasil MA \& Rudge MV. Morphometric study of placental villi and vessels in women with mild hyperglycemia or gestational or overt diabetes.
Diabetes Research and Clinical Practice 200778 65-71. (https://doi. org/10.1016/j.diabres.2007.01.023)

28 Kuzmicki M, Telejko B, Zonenberg A, Szamatowicz J, Kretowski A, Nikolajuk A, Laudanski P \& Gorska M. Circulating pro- and antiinflammatory cytokines in Polish women with gestational diabetes. Hormone and Metabolic Research 200840 556-560. (https://doi. org/10.1055/s-2008-1073166)

29 Mrizak I, Grissa O, Henault B, Fekih M, Bouslema A, Boumaiza I, Zaouali M, Tabka Z \& Khan NA. Placental infiltration of inflammatory markers in gestational diabetic women. General Physiology and Biophysics 201433 169-176. (https://doi.org/10.4149/ gpb_2013075)

30 Sisino G, Bouckenooghe T, Aurientis S, Fontaine P, Storme L \& Vambergue A. Diabetes during pregnancy influences Hofbauer cells, a subtype of placental macrophages, to acquire a pro-inflammatory phenotype. Biochimica et Biophysica Acta 20131832 1959-1968. (https://doi.org/10.1016/j.bbadis.2013.07.009)

31 Lindau R, Mehta RB, Lash GE, Papapavlou G, Boij R, Berg G, Jenmalm MC, Ernerudh J \& Svensson-Arvelund J. Interleukin-34 is present at the fetal-maternal interface and induces immunoregulatory macrophages of a decidual phenotype in vitro. Human Reproduction 201833 588-599. (https://doi.org/10.1093/ humrep/dey037)

Received in final form 14 October 2019

Accepted 24 October 2019

Accepted Preprint published online 24 October 2019
This work is licensed under a Creative Commons Attribution-NonCommercial 4.0 International License. ded from Bioscientifica.com at 04/26/2023 10:40:13AM 